Iranian Quarterly Journal of Breast Disease. 2019; 12(1):48-57.

\section{Original Article \\ Knowledge Attitude and Performance of Female Students of Medical versus Nonmedical Sciences toward Breast Self-examination}

\author{
Imani Ghoghary $\mathbf{Z}^{1}$, ZeidabadiNejad $\mathbf{M R}^{2}$, Balvardi $\mathbf{M}^{3^{*}}$ \\ ${ }^{1}$ Department of Nursing and Midwifery, Sirjan Faculty of Medical Sciences, Sirjan, \\ Iran \\ ${ }^{2}$ Department of Medical Emergency, Sirjan Faculty of Medical Sciences, Sirjan, Iran \\ ${ }^{3}$ Department of Biostatistics and Epidemiology, Sirjan Faculty of Medical Sciences, \\ Sirjan, Iran
}

Receive: 2019/2/10

Accepted: 2019/4/4

"Corresponding Author:

Mohadeseh Balvardi

mbalvardi_biostat90@yahoo.com

Ethics Approval: IR.SIRUMS.REC.1397.001

\begin{abstract}
Introduction: Breast cancer is the most common type of cancer in Women, which, if diagnosed at an early stage, can be treated. Breast selfexamination is a simple and inexpensive way to screen for breast cancer. Students, especially medical students, as the educated class of the community, are expected to be knowledgeable with good attitudes and performance in this field. The purpose of this study was to compare the knowledge, attitude and performance of female Students of medical versus nonmedical Sciences toward Breast Self-examination in the city of Sirjan.
\end{abstract}

Methods: In this cross-sectional study, 228 medical students and 240 nonmedical students were enrolled. A researcher-made survey questionnaire was used for data collection. Content validity of the questionnaire was confirmed by 10 nursing and midwifery experts, and its reliability was assessed by calculating Cronbach's alpha coefficient. Data were analyzed using SPSS software.

Results: The mean breast self-examination knowledge scores for medical students and nonmedical students were $34 \pm 3.81$ and $32.84 \pm 4.40$, respectively. The mean score of attitude toward breast self-examination was $68.11 \pm 8.69$ for medical students and $63.54 \pm 8.90$ for nonmedical students. Finally, the mean score of performance of breast self-examination was $23.88 \pm 6.37$ for medical students versus $22.89 \pm 7.45$ for nonmedical students. There was a significant difference in knowledge and attitude between medical and nonmedical students $(\mathrm{P}<0.05)$, but the difference in performance was not significant $(\mathrm{P}>0.05)$.

Conclusion: Knowledge scores of medical and nonmedical students were moderate, and attitude scores of both groups were high, although medical students' scores were significantly higher than those of nonmedical students. Nonetheless, both groups had poor performance of breast selfexamination. This indicates that efforts must be made on the part of the education system to promote awareness, attitude and performance of breast self-examination through effective and new methods.

Keywords: Breast Cancer, Breast Self-examination, Knowledge, Attitude, Performance 


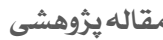

بررسى و مقايسه دانش، نكرش و عملكرد دانشجويان دختر علوم

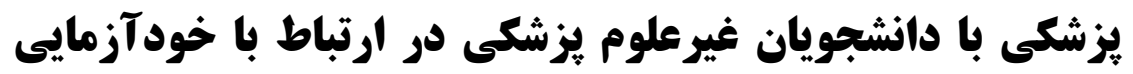

עיזتان

زهرا ايمانى Fوغرى'، محمدرضا زيد آبادى نزاد'، محدثه بلوردى"

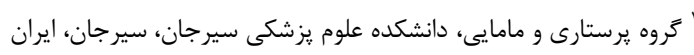

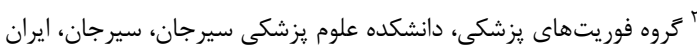

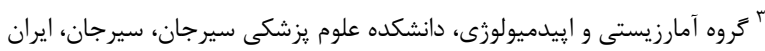

فصلنامه بيمارى هاى يستان ايران

IrqA! Ir(1): EA-Or

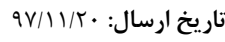
تاريخ بذيرش: T/I/TQ

نشانى نويسنده مسئول:

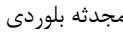
mbalvardi_biostat90@yahoo.com

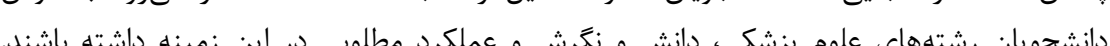

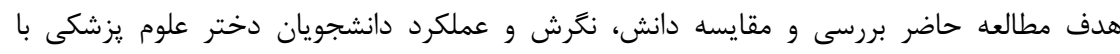

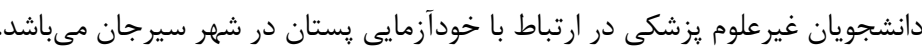
روش بررسى: در اين مطالعه مقطعى TrA نفر از دانشجويان رشتهاى علوم يزشكى و • ن. نفر از

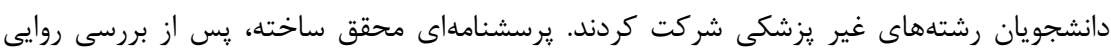

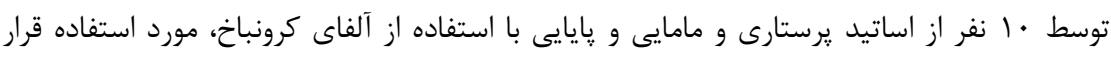

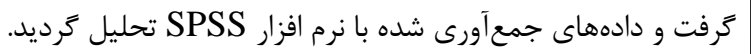

يافتهها: بر اساس نتايج حاصل از اين مطالعه، ميانگين نمرات دانش در ارتباط با خودآزمايى يستان

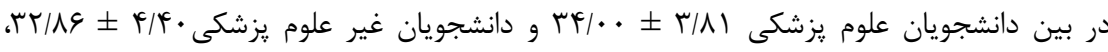

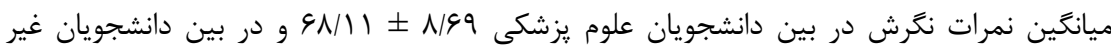
يزشكى • •

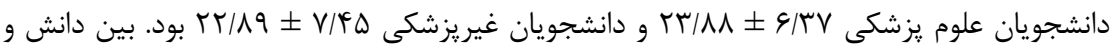

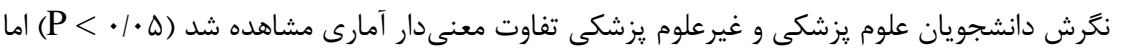

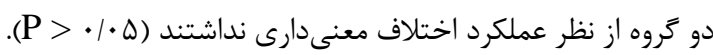
نتيجهَيرى: نمرات دانش دانشجويان علوم يزشكى و غيرعلوم يزشكى متوسط كزارش گرديد و

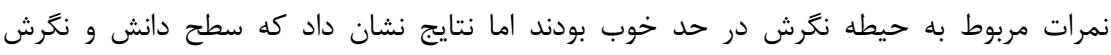

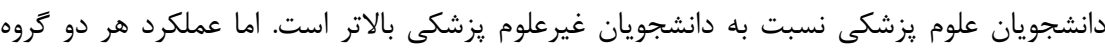

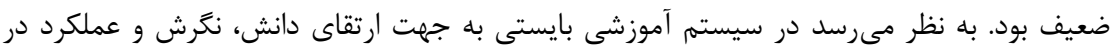

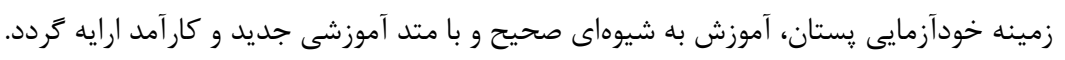
وازههاى كليدى: سرطان پِتان، خودآزمايى يُتان، دانش، نترش، عملكرد 


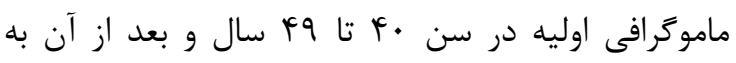

صورت ساليانه (r ال).

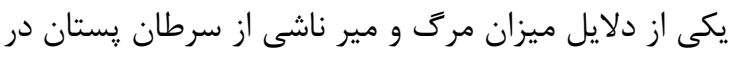

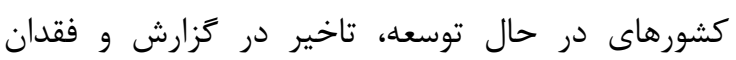

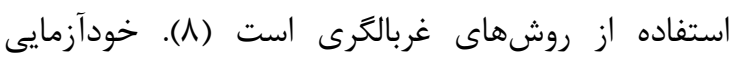

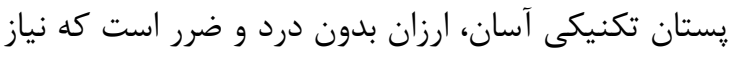

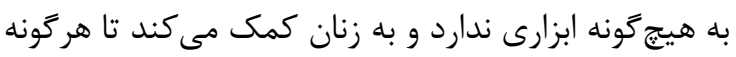

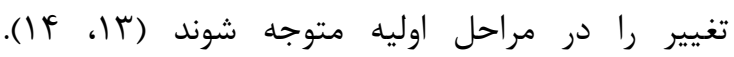
خودآزمايى يستان مىتواند در كشف موارد اوليه و مديريت

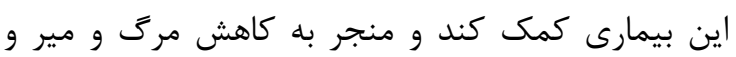
ناتوانى ناشى از آن شود (ه (1).

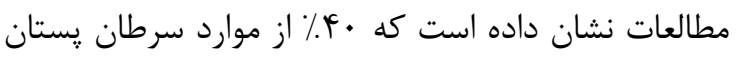

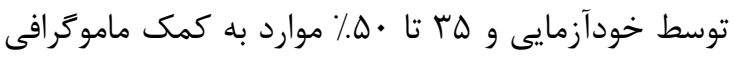

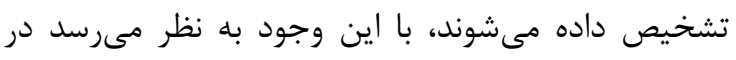

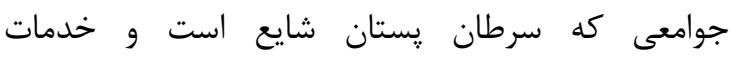

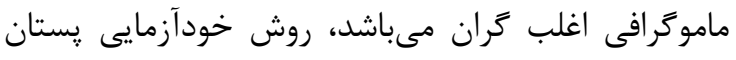

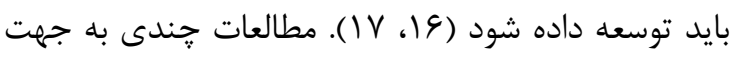
بررسى دانش، نكرش و عملكرد زنان در مورد خودآزمايى دادي

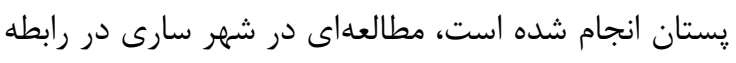

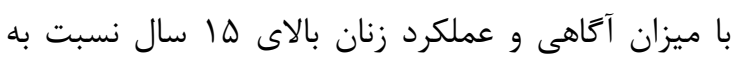

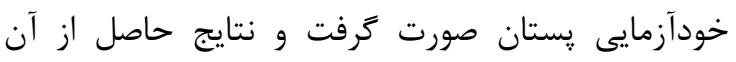

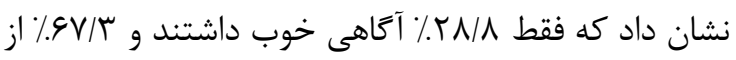

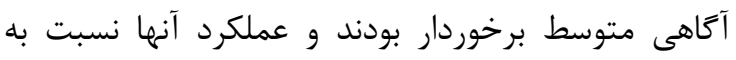

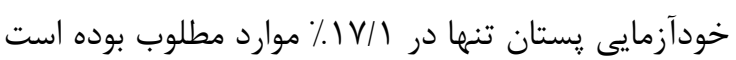

دانشجويان و دانشكاهيان قشر تحصيلكرده جامعه هستند كه انتظار مىرود در مسايل بهداشتى نسبت به به سائ سايرين دانش، نكرش و عملكردى بهتر داشته باشند، از سوى ديخر

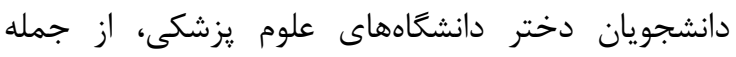

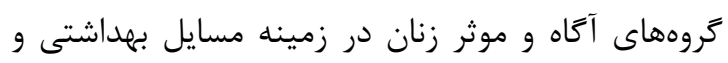

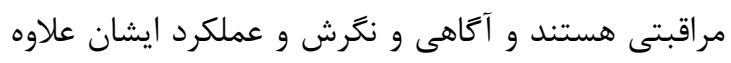

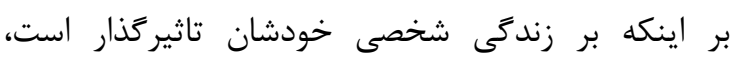

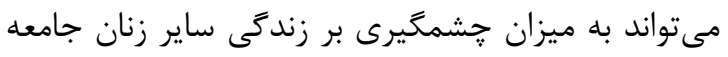

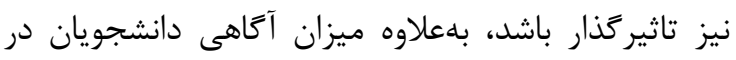

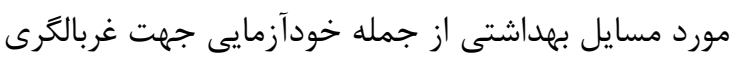

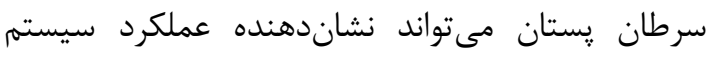

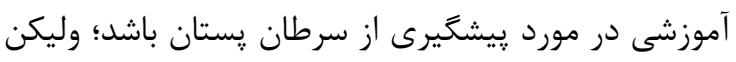

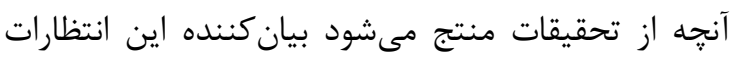

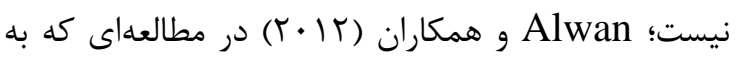

سرطان از جمله بيمارىهايى است كه به دليل ميزان بروز

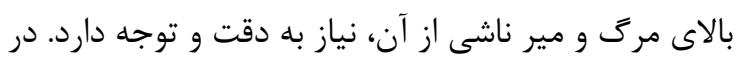

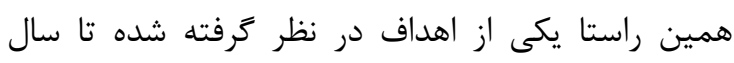

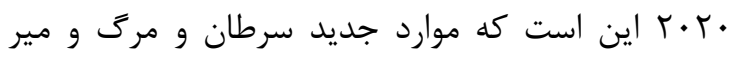

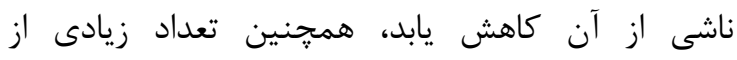

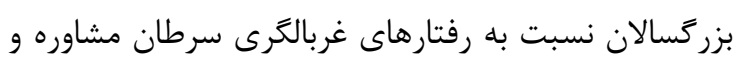

آموزش داده شوند (1). در بين انواع مختلف سرطان، سرطان يستان شايعترين

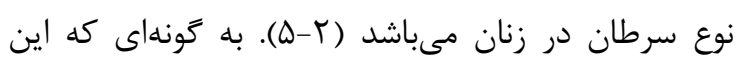

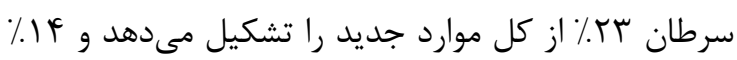

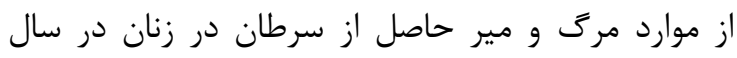

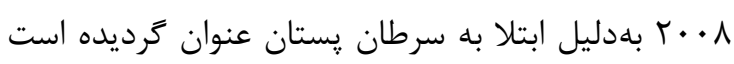

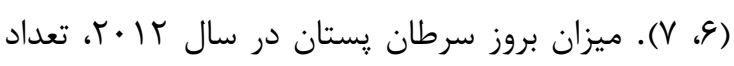

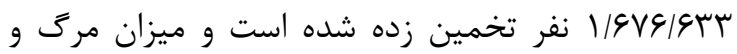

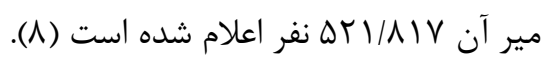

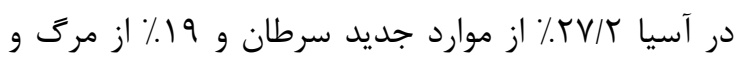

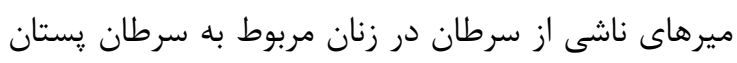

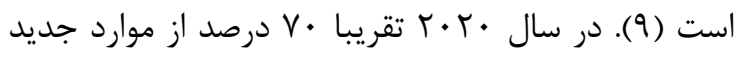

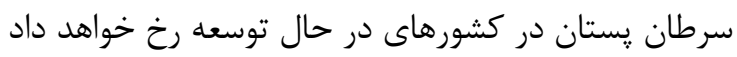

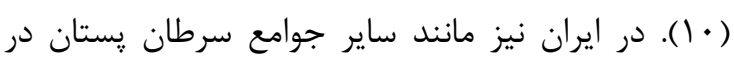

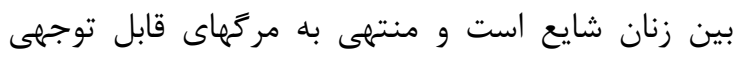
مىشود و هزينههاى زيادى بر دوش نظام سلامت تحميل

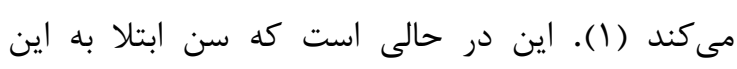

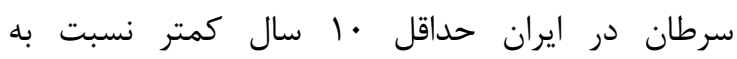

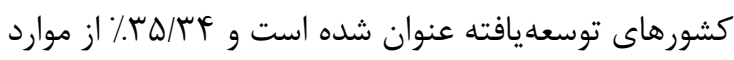

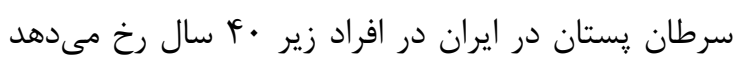

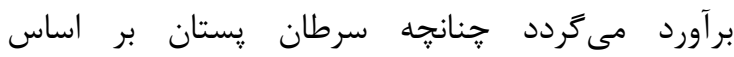

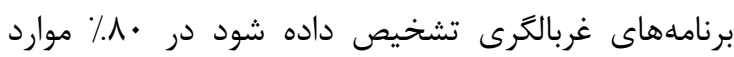

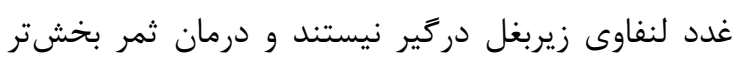
خواهد بود. بر همين اساس انجمن سرطان آمريكا به نديه

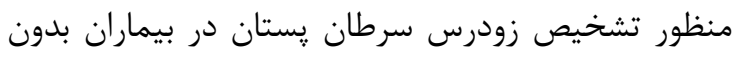

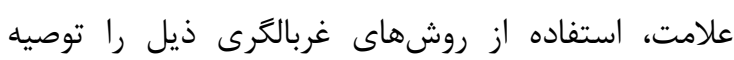

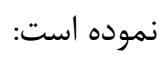

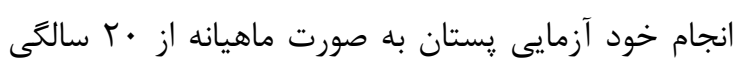

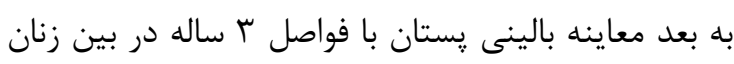

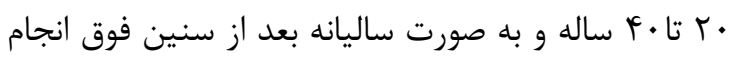




\section{مواد و روشها}

در اين مطالعه مقطعى جامعه آمارى مورد بررسى كليه

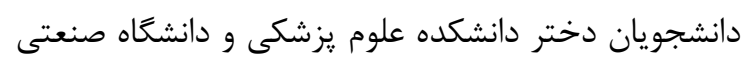

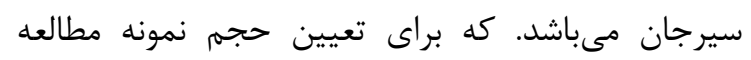
مقدماتى با حجم •V نفر انجام شد، با استفاده از فرمول بـان

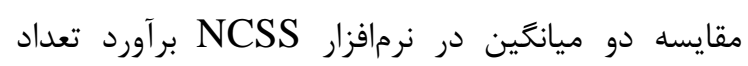

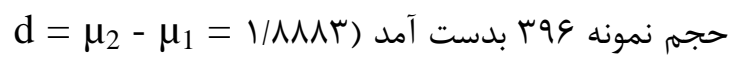
و

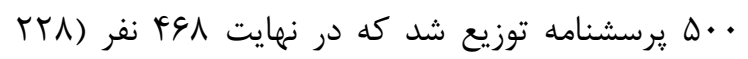

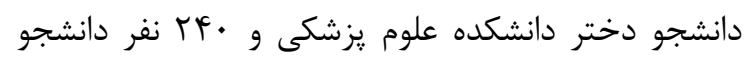

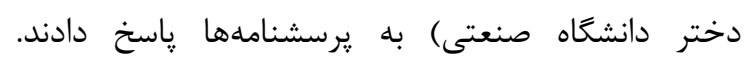
نمونهها بعد از بيان اهداف تحقيق، به نسبت دانشجويان

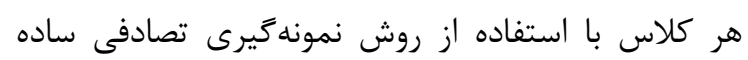

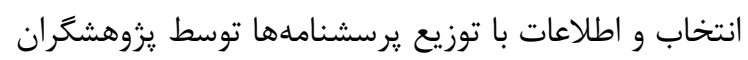
در هر دانشعاه جمعآورى گرديد.

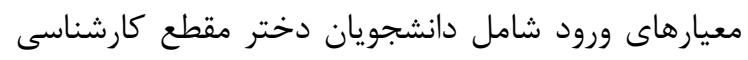

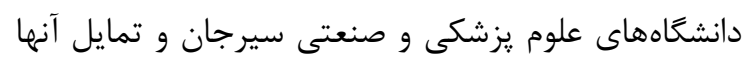
براى شركت در مطالعه بود. دانشجويان بدون معيارهاى فوق از مطالعه خارج شدند. در ابتداى كار كد اخلاق با بـ ديان

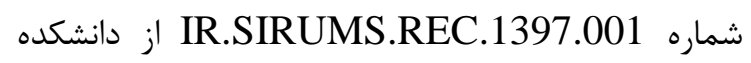
علوم يزشكى سيرجان اخذ شد. يس از كسب مجوزهاى

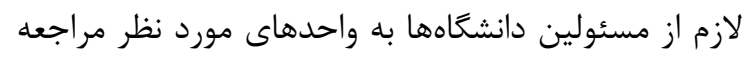

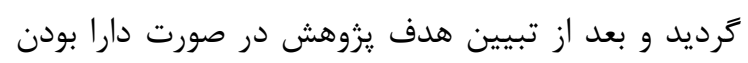
معيارهاى ورودى، فرم رضايت آكاهانه در اختيار افراد قرار داده و تكميل شد. به منظور جمع آورى اطلاعات در جهيل تهار بخش، اطلاعات

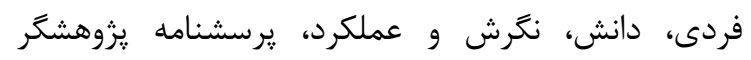

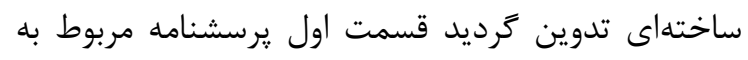

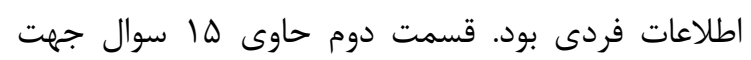

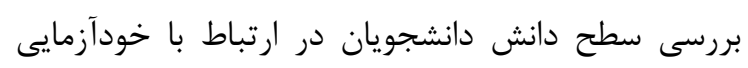

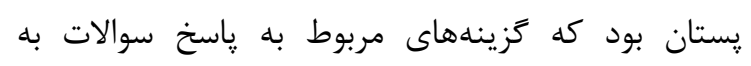

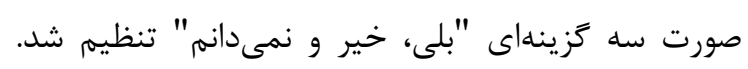

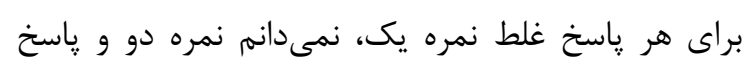

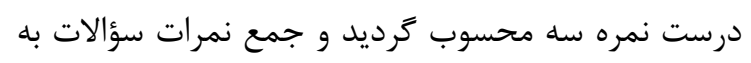

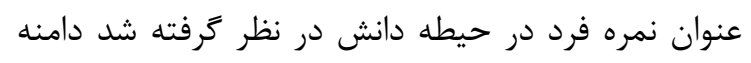

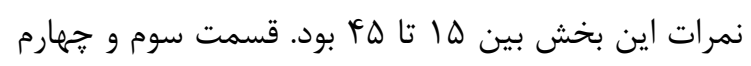

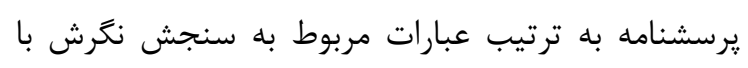

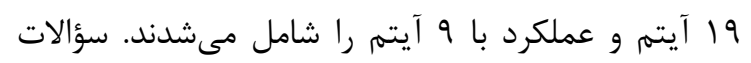
نَرشى بر اساس مقياس ه درجهاى ليكرت از كاملاً
جهت بررسى آكاهى، نكرش و عملكرد نمونهاى از جمعيت تحصيلكرده در عراق انجام دادند بيان كردند كه تنهيا

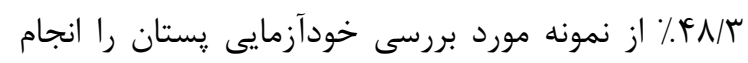

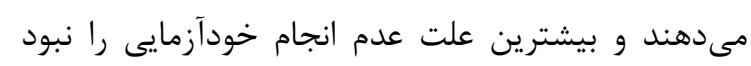

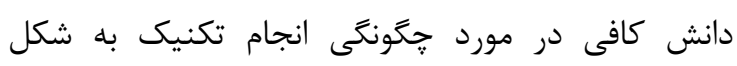

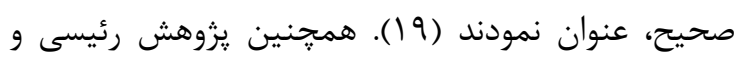
همكاران با هدف بررسى آكاهى، نخرش و عملكرد كاركنان

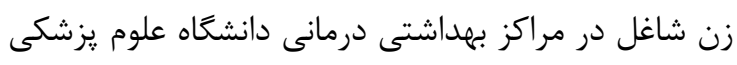

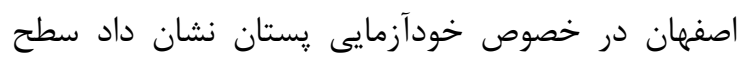

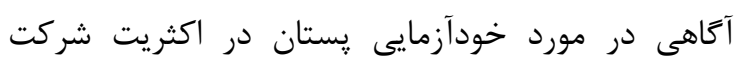

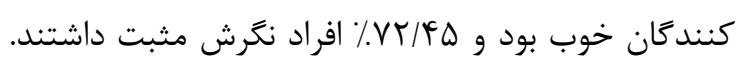

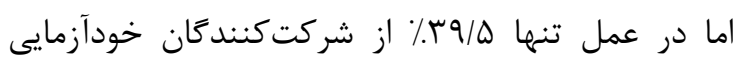

يستان را در هر ماه به طور منظم انجام مى دادند (·r).

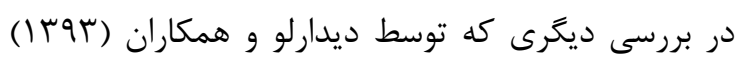

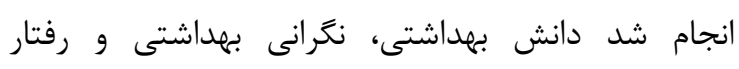

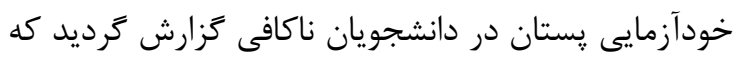

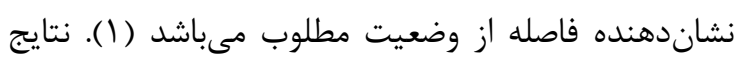
مطالعه شهبازى و حيدرى در سال سوسا نيز حاكى از آن

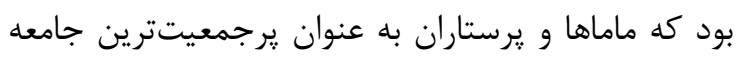

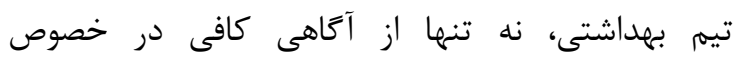

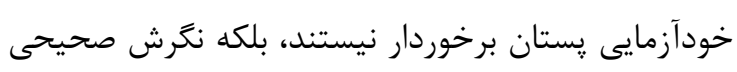

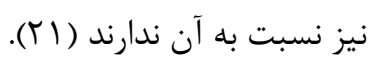

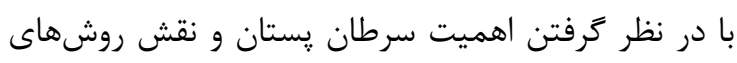
غربالكرى در ريشخيرى از آن و با توجه به اهميت موضوع

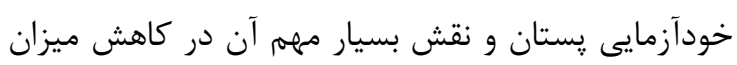

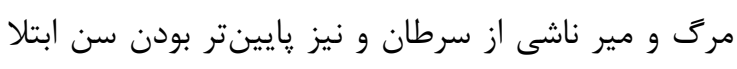

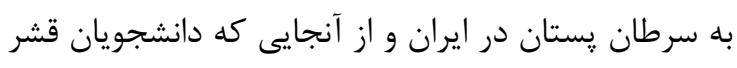

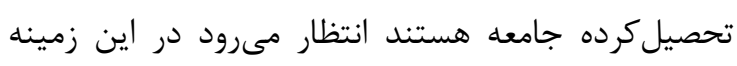
اطلاعات مناسبى داشته باشند و از سوى هوى ديخر انتظار مىرود آموختههاى ضمن تحصيل و ويزگ

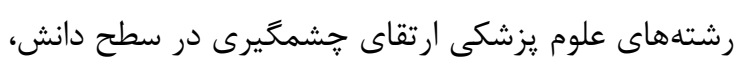

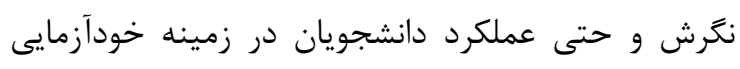
يستان نسبت به ساير دانشجويان ايجاد نمايد. بنابراين اين

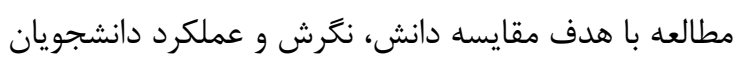
دختر دانشكده علوم يزشكى با دانشجويان دختر غيرعلوم

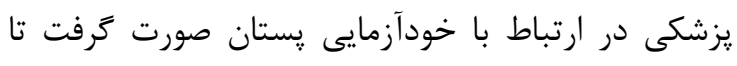

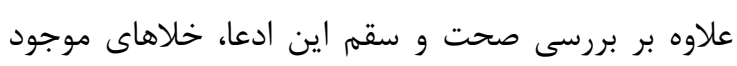

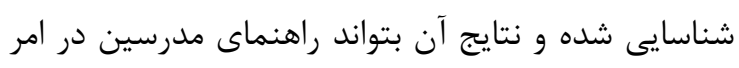

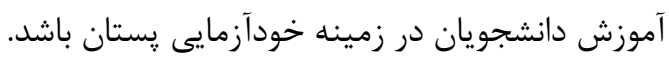


توصيفى از جداول توزيع فراوانى استفاده شد و در بخش

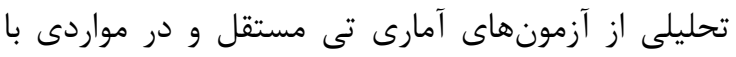

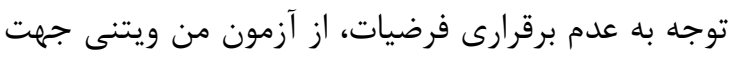
مقايسه سطح دانش، نكرش و عملكرد در دو تروه فرو استفاده كرديد. - مع

\section{كافتهها}

در اين يزوهش ده

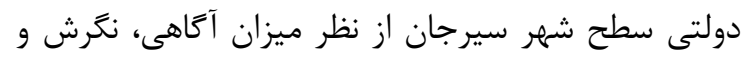

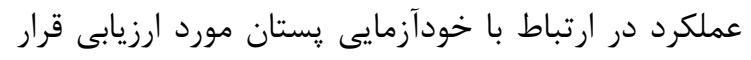

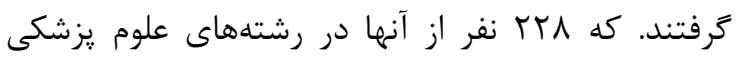

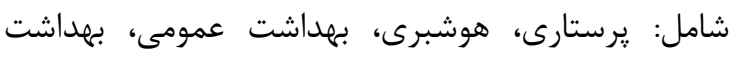

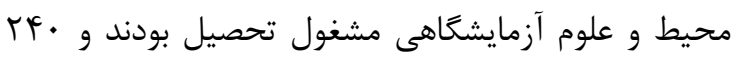

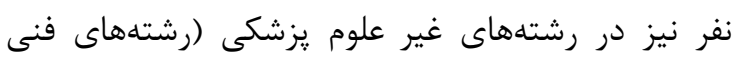

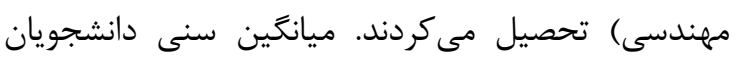

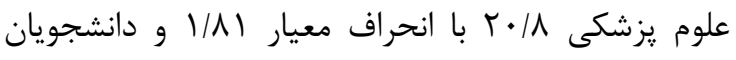

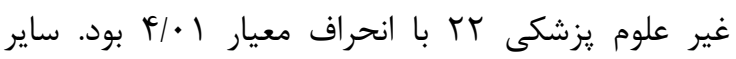

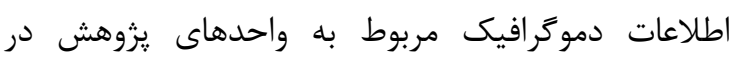
جدول شماره ا آورده شده است.
مخالف ( ) تا كاملاً موافق (ل) تنظيم شده بود كه جمع

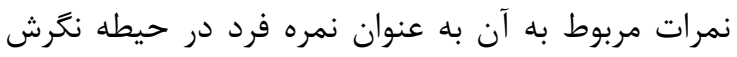

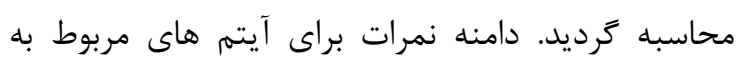

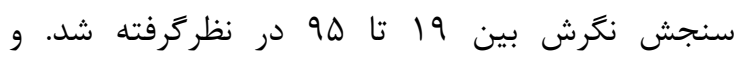

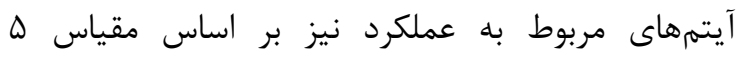

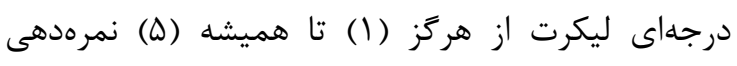

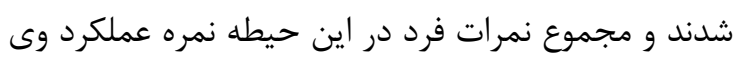

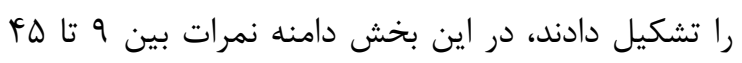

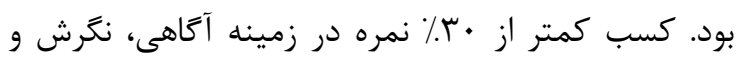

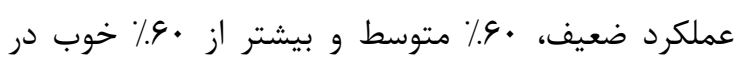

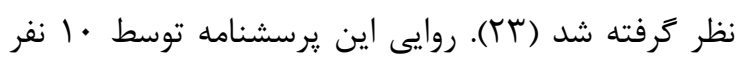

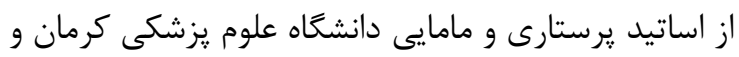

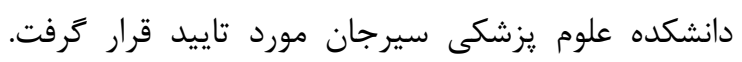

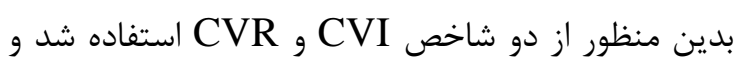

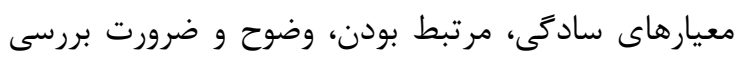

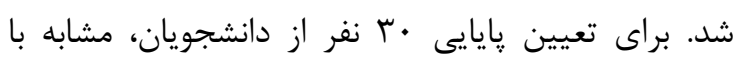

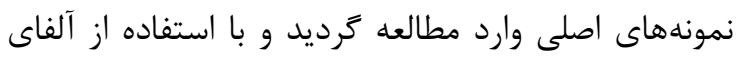

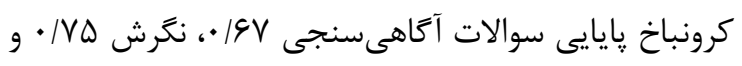

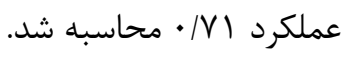

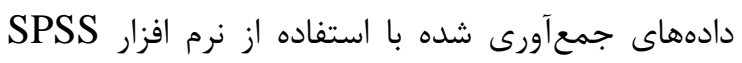

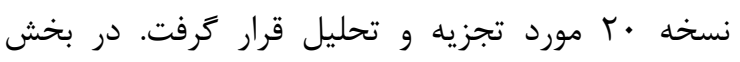

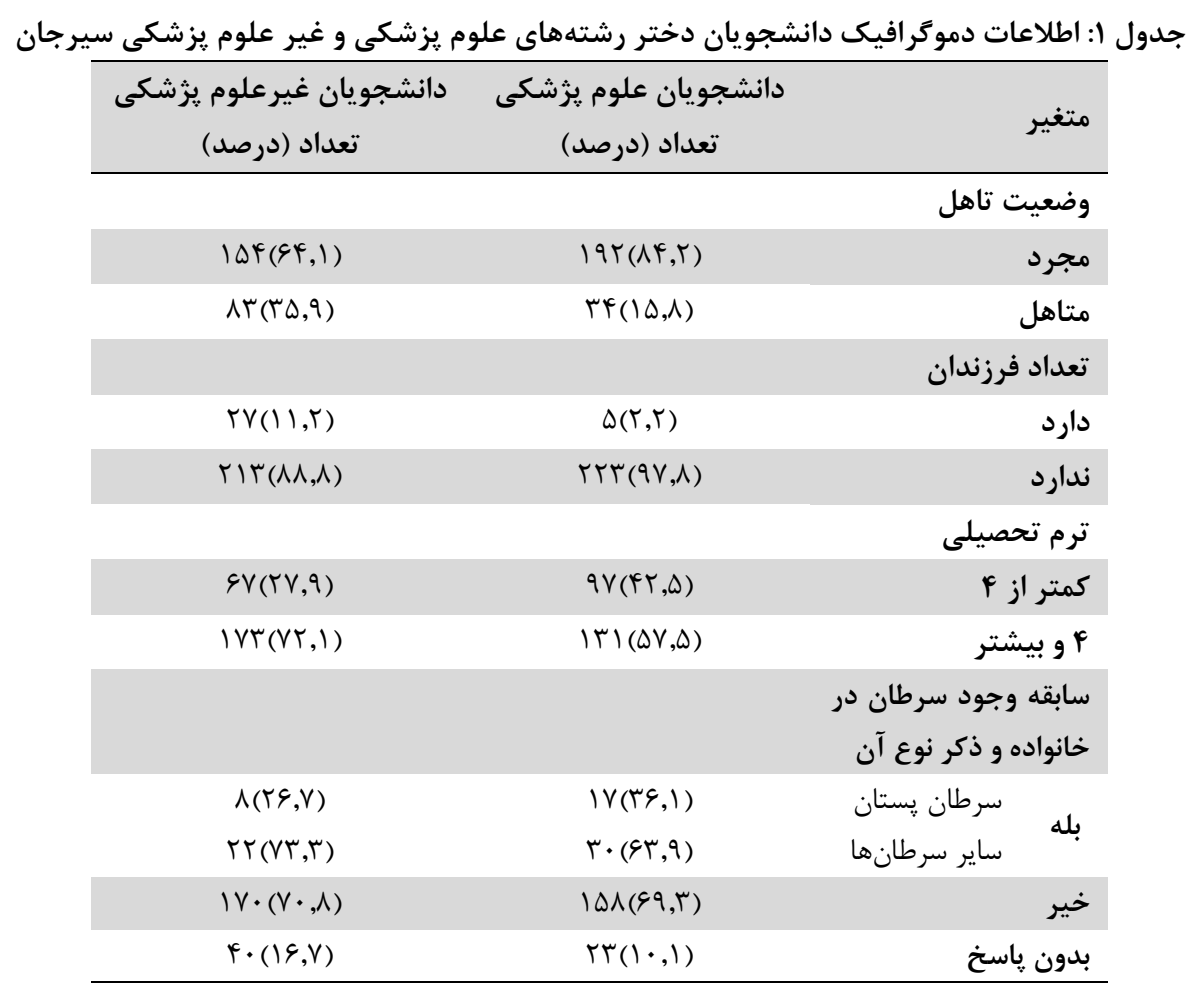


را در واحدهاى يزوهش به تفكيك نشان مى دهد. بر اساس

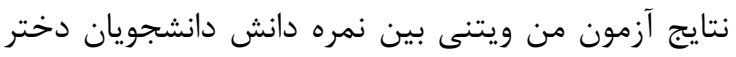

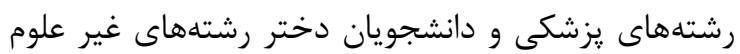

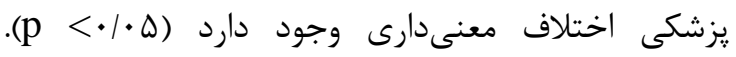

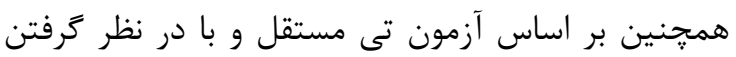

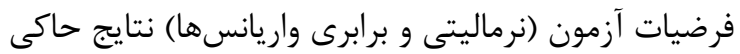
از اختلاف معنادار بين نمره نكرش دانشجويان دران دخران

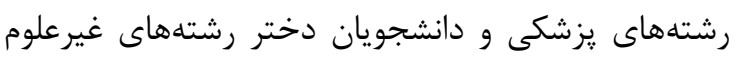
يزشكى (ه•|• p) و عدم اختلاف نمره عملكرد دو كروه

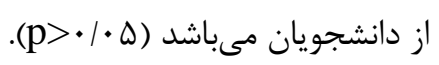

با استفاده از آمار توصيفى سطح دانش، نكرش و عملكرد

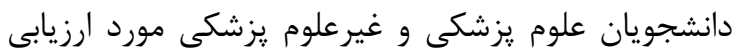

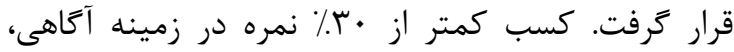

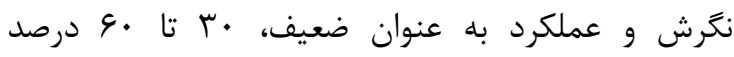
متوسط و بيش از • 9٪ خوب در نظر كرفته شد. نتايج در جدول شماره Y كزارش شده است. جهت مقايسه سطح دانش، نكرش و عملكرد دانشجويان علوم يزشكى با دانشجويان غير علوم يزشكى از آزمونهائ آمارى تى مستقل و من ويتنى استفاده شد. جدول شماره r ميانكَين و انحراف معيار نمرات دانش، نكخرش و عملكرد

\begin{tabular}{|c|c|c|c|c|}
\hline عملكرد (درصد) & نَخرش (درصد) & دانش (درصد) & & مقياس ارزيابى \\
\hline$\wedge \varepsilon, \wedge$ & $\cdot$ & $T Y, 1$ & ضعيف & \\
\hline Ir, & $I V, \Delta$ & $V \Delta, 9$ & متوسط & دانشجويان علوم يزشكى \\
\hline · & $\wedge r, \Delta$ & · & خوب & \\
\hline$\wedge \vee, 1$ & $\cdot$ & rT, & ضعيف & \\
\hline $1 T, 9$ & ५१,६ & $9 V, 1$ & متوسط & دانشجويان غيرعلوم يزشكى \\
\hline$\cdot$ & $4 \cdot, r$ & · & خوب & \\
\hline
\end{tabular}

جدول rا: مقايسه ميانكَين و انحراف معيار نمرات دانش، نتحرش و عملكرد دانشجويان دختر علوم يزشكى و غير علوم يزشكى سيرجان

\begin{tabular}{|c|c|c|c|}
\hline p-value & 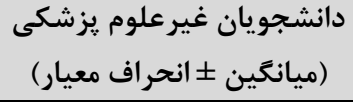 & 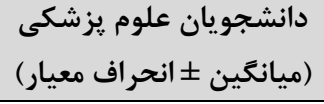 & متغير \\
\hline$\cdot, \cdots r$ & $r, r \cdot \pm r r, \wedge \varepsilon$ & $r r, \cdots \pm r, \wedge l$ & آكاهى \\
\hline$<\cdot, \cdot \cdot 1$ & $\Lambda, q \cdot \pm q \Psi, \Delta F$ & $\wedge, 99 \pm 9 \wedge, 11$ & نكَرش \\
\hline • & $\checkmark, \varphi_{\Delta} \pm r r, \wedge q$ & $\varepsilon, r V \pm r r, \wedge \Lambda$ & عملكرد \\
\hline
\end{tabular}

داشتند. در مطالعه انورى و همكاران (T/ (Y) نيز دانش

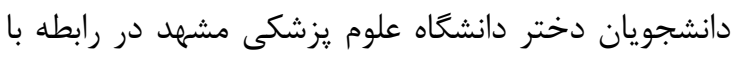

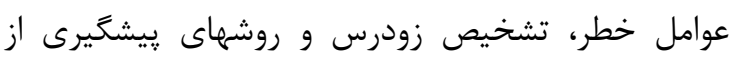

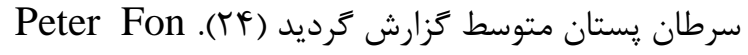
Nde

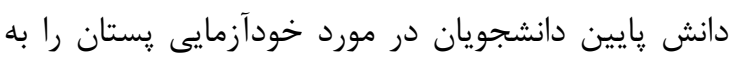

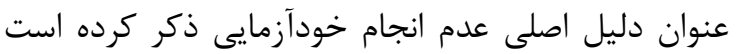

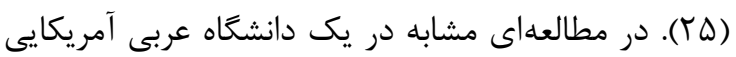

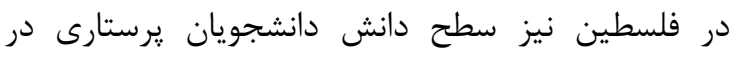

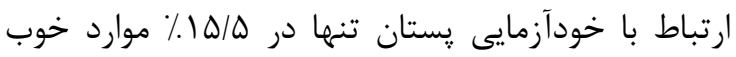

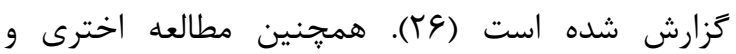

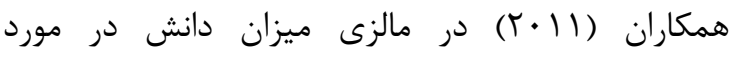

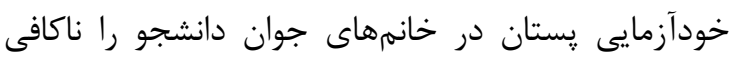

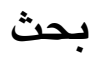

اين مطالعه به بررسى و مقايسه سطح دانش، نكرش و

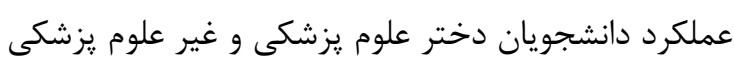

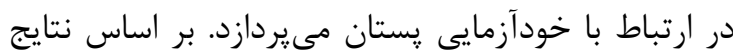

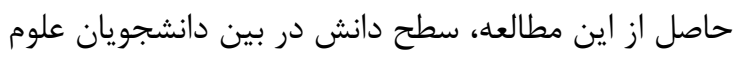

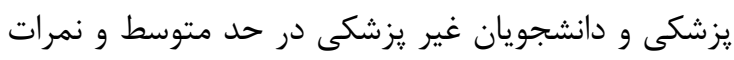

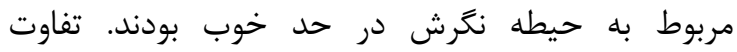

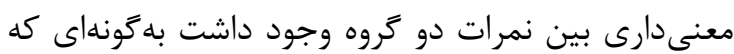

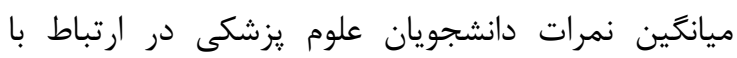

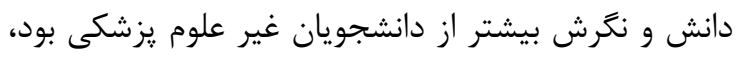
اما اين اختلاف در ارتباط با ميانخين نمرات عملكرد

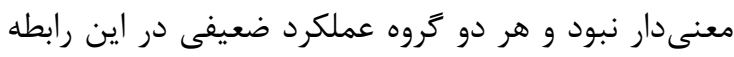


كردند. مطالعات ديخرى نيز نكَرش دانشجويان علوم

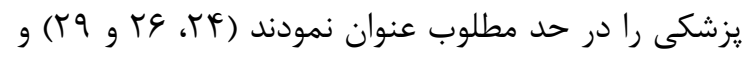

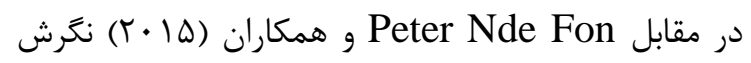

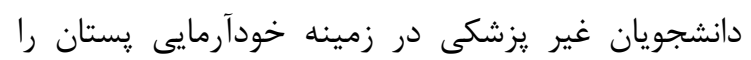

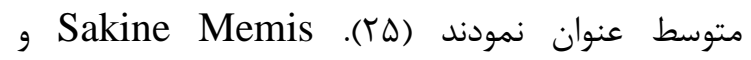

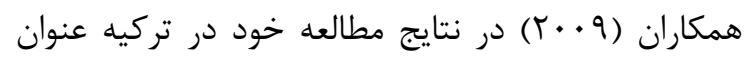

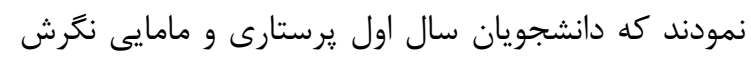

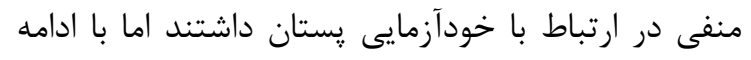

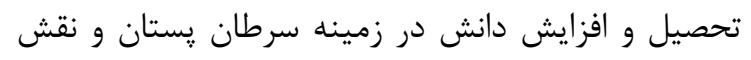

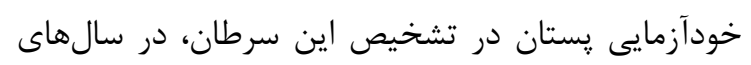

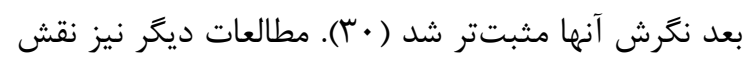

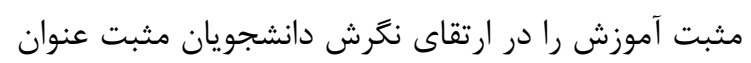

نمودند (1) (1).

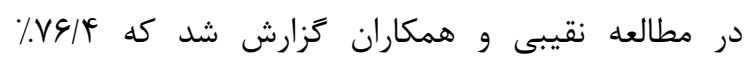

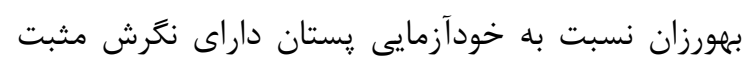

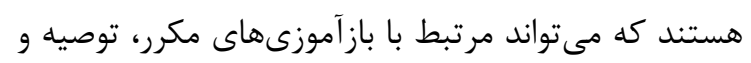

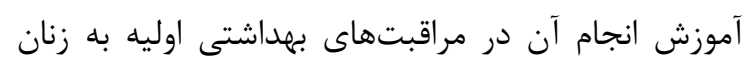

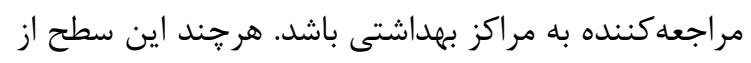

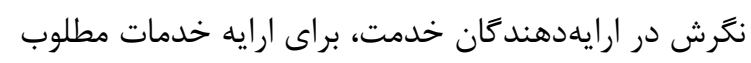

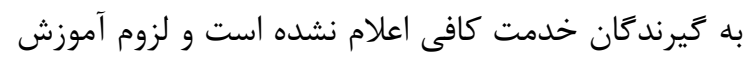

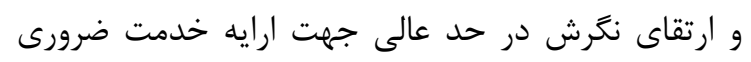

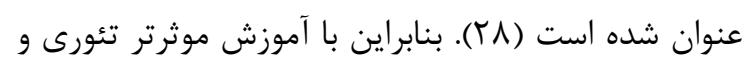

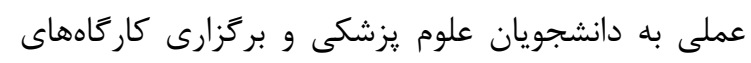

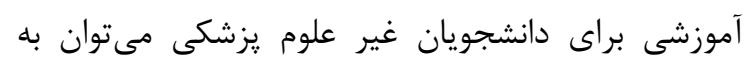
ارتقاى سطح نحرش كمك شايانى نمود.

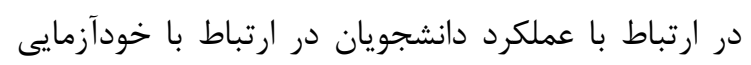

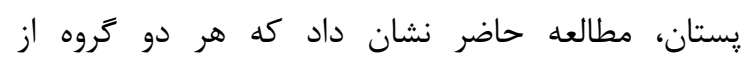

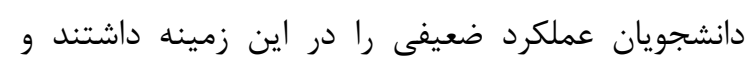

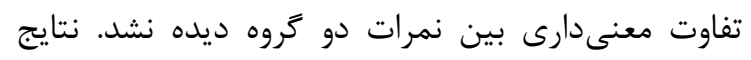

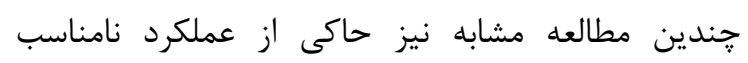

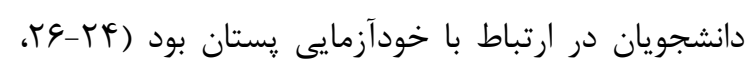

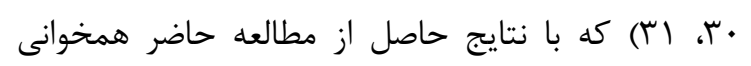

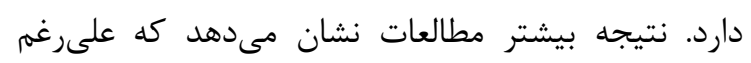

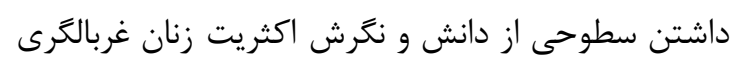

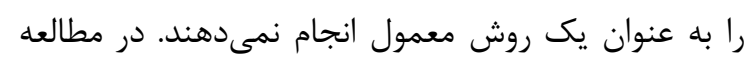

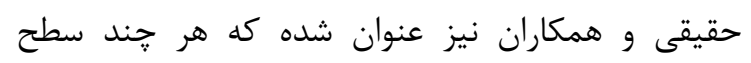

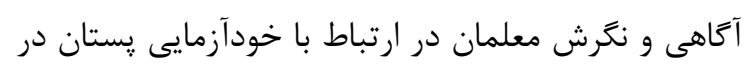

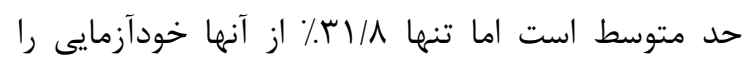
انجام مىدادند و بيشترين دليل آن را عدم آشنايى با آنا
عنوان كرد (YV). نتايج حاصل از مطالعات مختلف هم

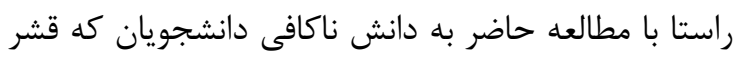

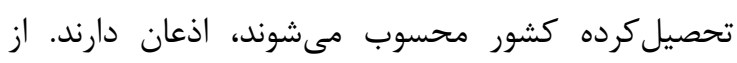

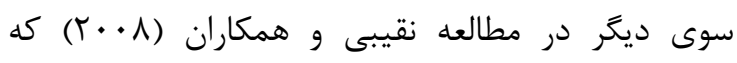
جامعه هدف بهورزان بودند سطح آكاهى بهورزان در دمر مورد

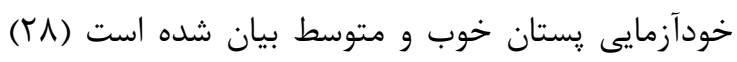
اين مسئله مىتواند بيان كننده اين مطلب باشد كه بهون بهورزان

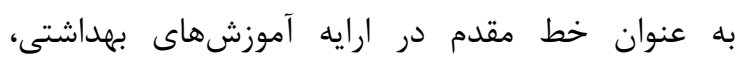

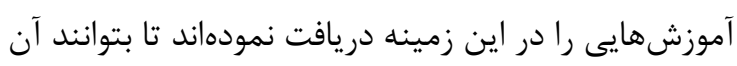

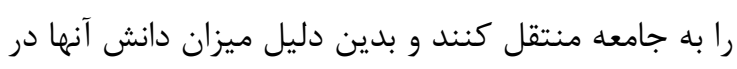

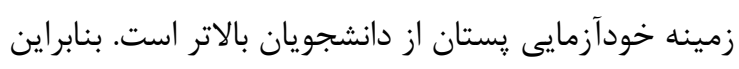

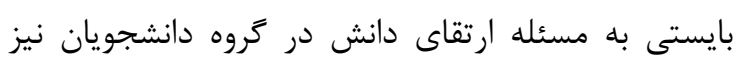
توجه شود.

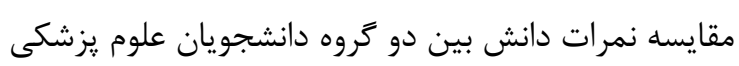

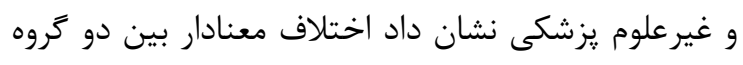

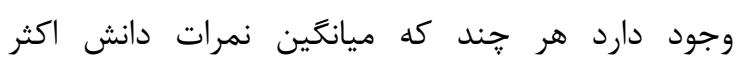

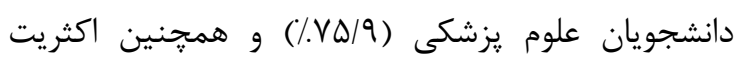

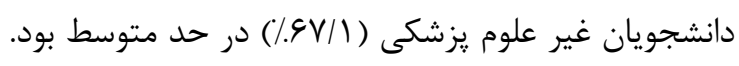

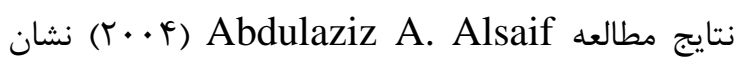
داد كه سطح دانش دانشجويان در زمينه خودآزمايى

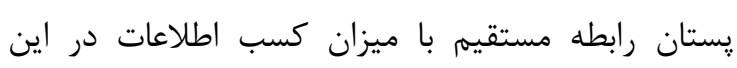

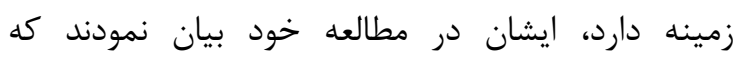
دانشجويان يرستارى كه آموزش بيشترى دران در زمينه

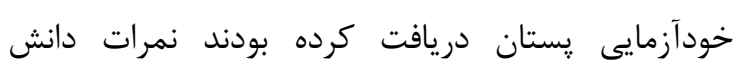

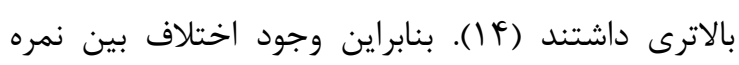
دانش در بين دانشجويان علوم يزشكى و غيرعلوم يزشكى دابنى

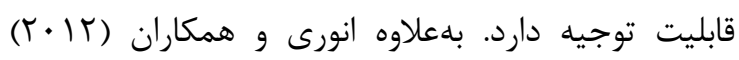
عنوان نمودند كه دانشجويان رشتههاى بالينى نمره دانش

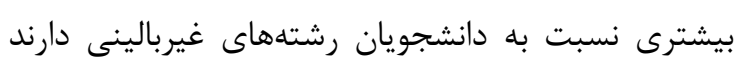

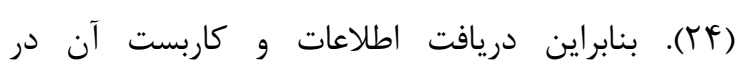

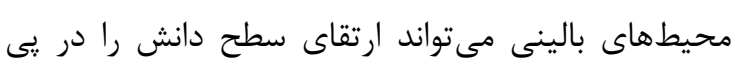
داشته باشد. بهعلاوه نتايج مطالعه حاضر نشان داد كه هر دو تروه از

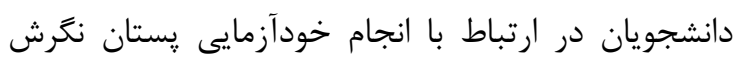

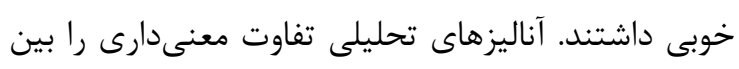

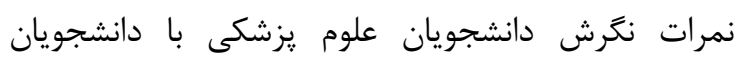

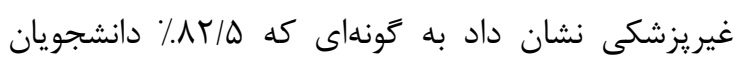

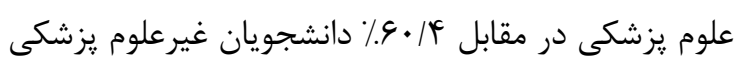

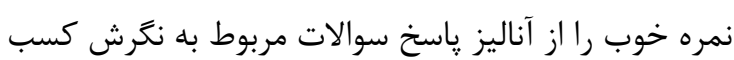


سرطان يُتان تنها در خانمهاى با سن بالا بروز مى كند و

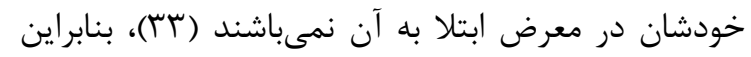

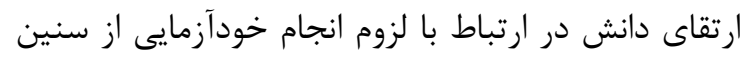

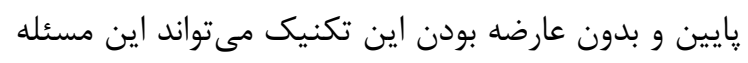

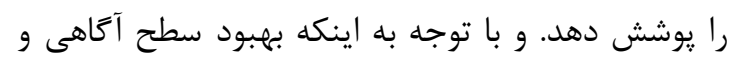

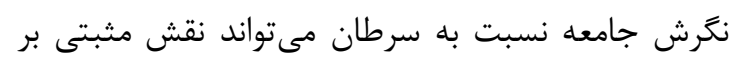

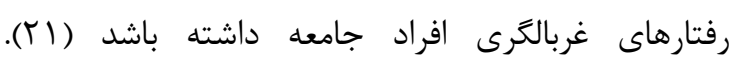

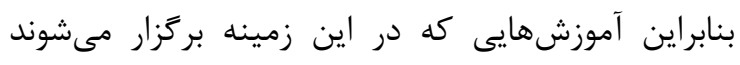

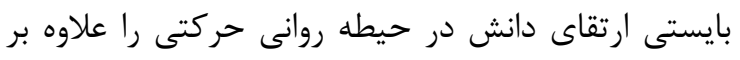
حيطههاى شناختى و عاطفى مدنظر قرار دهند.

\section{نتيجهكيرى}

شواهد حاصل از اين مطالعه هم راستا با ساير مطالعات

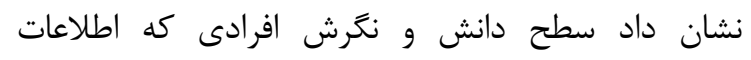
بيشترى دريافت كردهاند يا در محيطهاى باليتى قرار

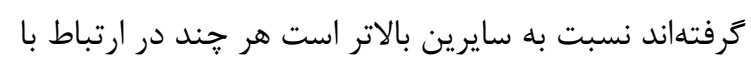
عملكرد نتايج حاصل از مطالعه نشاندهنده عملكرد ضعيف باني

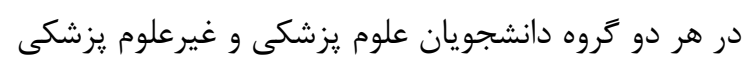

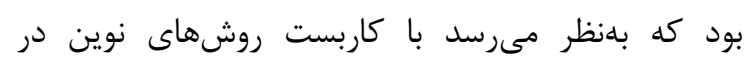

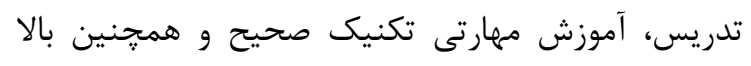

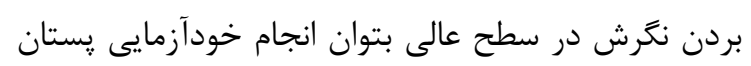

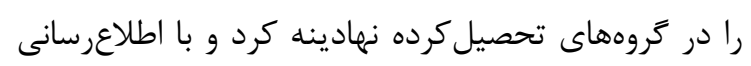

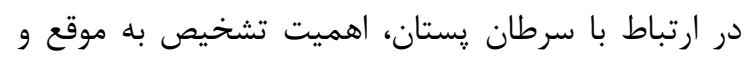

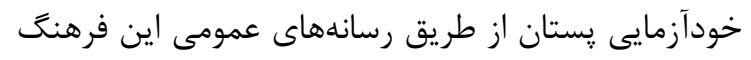

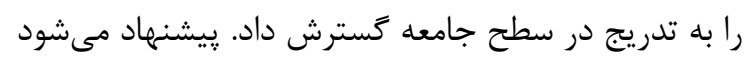

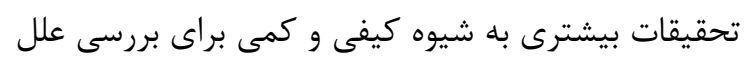

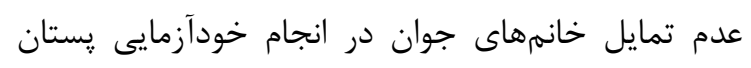
صورت يذيرد و بعلاوه در تحقيقات آتى تاثير روشهاى فيلى فعال

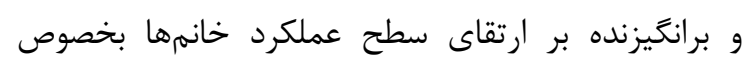

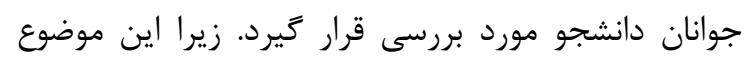
براى دانشجويان علوم يزشكى كه مسئول ارايه خدمات

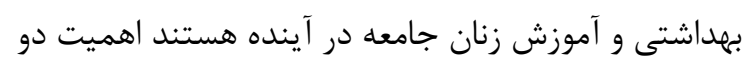

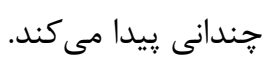

\section{تعارض منافع}

نويسند

يزوهش حاضر وجود ندارد.
تكنيك معاينه و محتمل نداشتن وجود مشكل در يستان

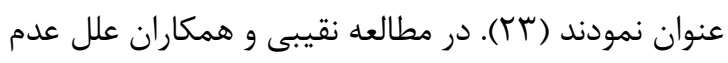

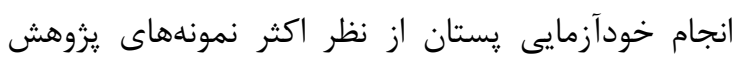

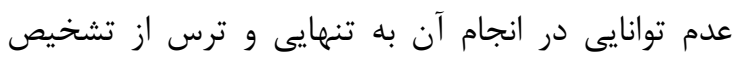

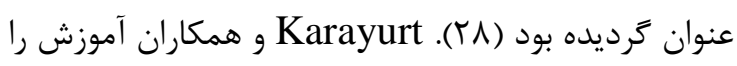

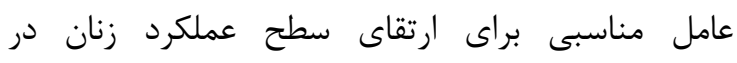

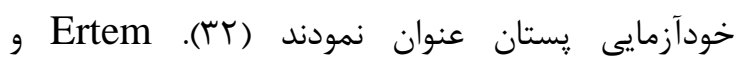
همكاران نيز در نتايج مطالعه خود عنوان نمودند كه اصولان

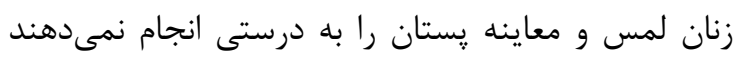

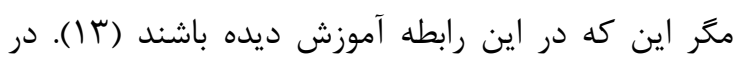
مطالعه Memis و همكاران هر خهند نيمى از داز دانشجويان

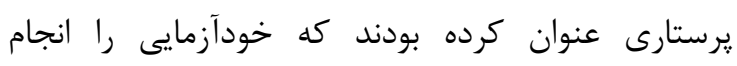

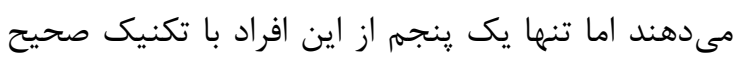

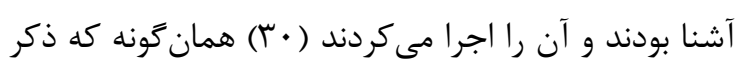

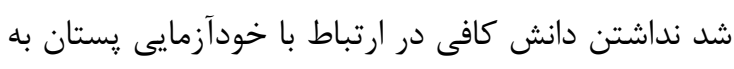

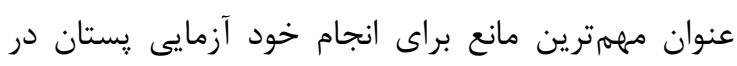
مطالعات متعدد عنوان شده است و در مطالعه مانه حاضر نيز

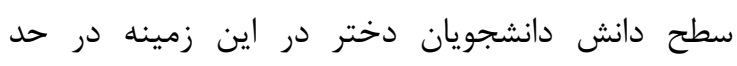

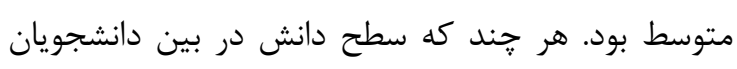

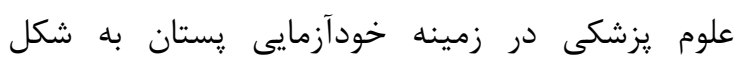

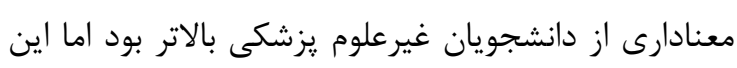

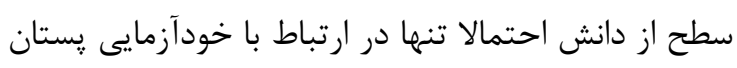

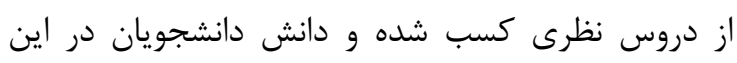
زمينه به سطوح بالاتر دانش مانند بكار بردن نرسيده است دان.

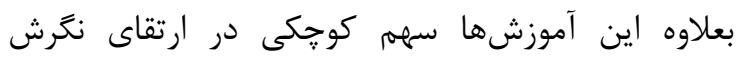

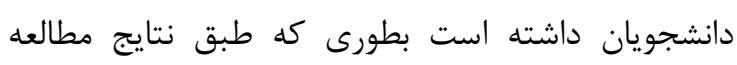

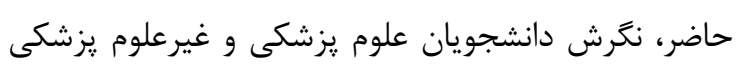

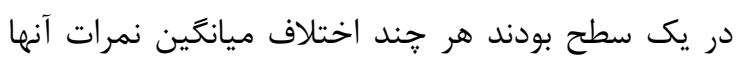

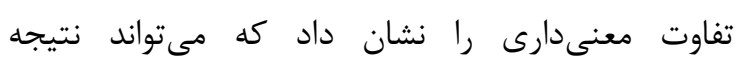

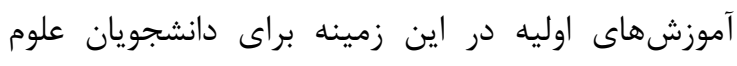

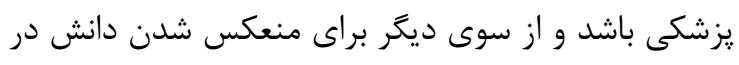

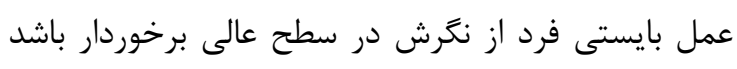
(YN)

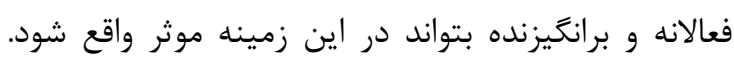

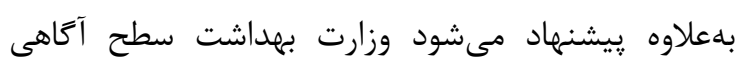

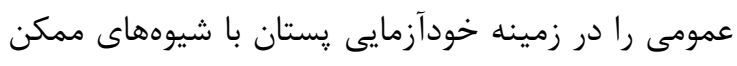

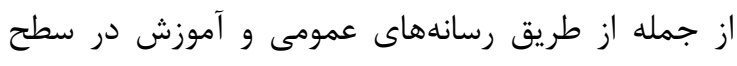

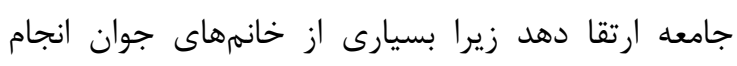

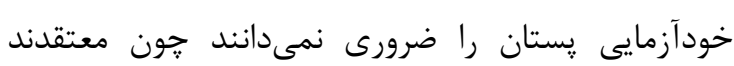




\section{References}

1. Didarloo a, Shorkhabi z, Pourali R. survey of knowledge, worry and screening behavior towards breast cancea among female students of urmia university of medical sciences, in 2014. Journal of Urmia Nursing And Midwifery Faculty. 2016;14(3):201-12.

2. Pimhanam C, Sangrajrang S, Ekpanyaskul C. Tobacco smoke exposure and breast cancer risk in Thai urban females. Asian Pac J Cancer Prev. 2014;15(17):7407.

3. Vakili M, Pirdehghan A, Adimi M, Sadeghian M, Akhondi M. Epidemiology and trend of cancer in Yazd, a central province of Iran, 2005-2009. Journal of research in health sciences. 2014;14(3):210-3.

4. Amoori N, Mirzaei M, Cheraghi M. Incidence of cancers in Kuzestan province of Iran: trend from 2004 to 2008. Asian Pac J Cancer Prev. 2014;15(19):8345-9.

5. Norouzi Nejad F, Ramezani Daryasar R, Ghafari F. Epidemiology of cancer in Mazandaran province 2006. Journal of Mazandaran University of Medical Sciences. 2009;19(72):61-5.

6. Ferlay J, Shin HR, Bray F, Forman D, Mathers C, Parkin DM. Estimates of worldwide burden of cancer in 2008: Globocan 2008. International journal of cancer. 2010;127(12):2893-917.

7. Jemal A, Bray F, Center MM, Ferlay J, Ward E, Forman D. Global cancer statistics. CA: a cancer journal for clinicians. 2011;61(2):69-90.

8. Kudzawu E, Agbokey F, Ahorlu CS. A Cross Sectional Study of the Knowledge and Practice of Self-Breast Examination among Market Women at the Makola Shopping Mall, Accra, Ghana. Advances in Breast Cancer Research. 2016;5(3):111.

9. Jafari-Koshki T, Schmid VJ, Mahaki B. Trends of breast cancer incidence in Iran during 20042008: A Bayesian space-time model. Asian Pac J Cancer Prev. 2014;15(4):1557-61.

10. Taheri NS, Nosrat SB, Aarabi M, Tabiei MN, Kashani E, Rajaei S, et al. Epidemiological pattern of breast cancer in Iranian women: is there an ethnic disparity? Asian Pacific Journal of Cancer Prevention. 2012;13(9):4517-20.

11. Almassi NF, Akbari H, Madani S, Izadi B, Emami AAM. Incidence of breast cancer in breast sample pathology reports in Iran (Kermanshah) 2001-2004. Iranian journal of obstetrics gynecology and infertility 2005;8(2):23-28.

12. Karimi M, Hasani M, Khoram R, Gafari M, Niknami S. The Effect of Education, Based on Health Belief Model on Breast SelfExamination in Health Liaisons of Zarandieh City. Zahedan Journal of Research in Medical Sciences. 2008;10(4):283-91.

13. Ertem G, Dönmez YC, Dolgun E. Determination of the Health Belief and Attitude of Women Regarding Breast Cancer and Breast Self-Exam. The Journal of Breast Health. 2017;13(2):62.

14. Alsaif AA. Breast self-examination among Saudi female nursing students in Saudi Arabia. Saudi Med J. 2004;25(11):1574-8.

15. Weiss NS. Breast Cancer Mortality in Relation to Clinical Breast Examination and Breast Self-Examination. The breast journal. 2003;9:s86-9.

16. Khani H, Moslemi Zadeh N, Montazeri a, Godazandeh G, Ghorbani A. Knowledge, attitude and practice of health personnel to prevention programs about breast cancer in southern margin of the caspian sea. Iranian Quaterly journal of Breast Disease. 2008;1(2):28-38.

17. Mohamed HAE-A, Ibrahim YM, Lamadah SM, Hassan M, El-Magd A. Application of the Health Belief Model for Breast Cancer Screening and Implementation of Breast SelfExamination Educational Program for Female Students of Selected Medical and Non-Medical Faculties at Umm al Qura University. Life Science Journal. 2016;13(5):21-33.

18. Ghorbani M, Abdolahi A, Royani S, Azizi R. Comparison Knowledge, attitude and practice of Barest self Examination. Iranian journal of breast disease. 2009; 2(3):36-42.

19. Alwan NA, Al-Diwan JK, Wafa'M A-A, Eliessa RA. Knowledge, attitude \& practice towards breast cancer \& breast self examination in Kirkuk University, Iraq. Asian Pacific Journal of Reproduction. 2012;1(4):308-11.

20. Reisi M, Javadzade SH, Sharifirad G. Knowledge, attitudes, and practice of breast self-examination among female health workers in Isfahan, Iran. Journal of education and health promotion. 2013;2(46):1-5.

21. Shahbazi S, Heidari M. Assessment of the knowledge and attitudes of nursing and midwifery personnel about Breast Self- 
Examination. The Iranian Journal of Obstetrics, Gynecology and Infertility. 2014;17(123):7-12.

22. Ghaem H, Jafari $\mathrm{P}$, Moslehi S. A comparison of the knowledge of breast selfexamination in female students of Shiraz university of medical sciences and those of shiraz university of sciences, 2004. Razi Journal of Medical Sciences. 2008;15(58):14553.

23. Haghighi F, Portaghali P, Javanbakht LR, Ghanbarzadeh N, Hosseini S, Haghighi F, et al. Knowledge, attitude, and practice of female teachers regarding breast cancer screening in Birjand. Modern Care Journal. 2012;9(2):14655.

24. Anvari K, Mousavi HS, Kavossi F, Mahdi ST. Evaluation of knowledge, attitude and practice of female students of Mashhad University of Medical Sciences regarding risk factors, early diagnosis and breast cancer prevention methods. journal of Breast disease. 2012;5(2):30-43.

25. Nde FP, Assob JCN, Kwenti TE, Njunda AL, Tainenbe TRG. Knowledge, attitude and practice of breast self-examination among female undergraduate students in the University of Buea. BMC research notes. 2015;8(1):43.

26. Ayed A, Eqtait F, Harazneh L, Fashafsheh I, Nazzal S, Talahmeh B, et al. Breast SelfExamination in Terms of Knowledge, Attitude, and Practice among Nursing Students of Arab American University/Jenin. Journal of Education and Practice. 2015;6(4):37-47.

27. Akhtari-Zavare ZIM, Hanafiah JM, Abdul MR, Zarina II. Knowledge on breast cancer and practice of breast self examination among selected female university students in
Malaysia. Medical Health and Science Journal. 2011;7(3):49-56.

28. Nighibi SA, Shahi KV, Yazdani J, Nowshani F. Knowledge, attitude and practice of the female health care provider in Maku city about breast self-examination. Journal of the School of Public Health and the Institute of Public Health Research. 2008;7(2):61-8.

29. Alsaraireh A, Darawad MW. Breast cancer awareness, attitude and practices among female university students: A descriptive study from Jordan. Health care for women international. 2018;39(5):571-83.

30. Memis S, Balkaya NA, Demirkiran F, editors. Knowledge, attitudes, and behaviors of nursing and midwifery students regarding breast self-examination in Turkey. Oncology nursing forum. 2009;36(1):39-46.

31. Al-Sharbatti SS, Shaikh RB, Mathew E, AlBiate MAS. Breast self examination practice and breast cancer risk perception among female university students in Ajman. Asian Pacific Journal of Cancer Prevention. 2013;14(8):4919-23.

32. Karayurt Ö, Dicle A, Malak AT. Effects of peer and group education on knowledge, beliefs and breast self-examination practice among university students in Turkey. Turkish Journal of Medical Sciences. 2009;39(1):5966.

33. Segni MT, Tadesse DM, Amdemichael R, Demissie HF. Breast self-examination: knowledge, attitude, and practice among female health science students at Adama Science and Technology University, Ethiopia. Gynecol Obstet (Sunnyvale). 2016;6(368):1-6. 